\title{
O CONTEÚdO CONSTITUCIONAL DA EDUCAÇÃO: CONTRIBUIÇÕES DA TRANSDISCIPLINARIDADE PARA UM ENSINO JURÍDICO LIBERTADOR E PROMOTOR DA CIDADANIA
}

\author{
Max Emiliano da Silva Sena ${ }^{1}$ \\ Frederico de Andrade Gabrich ${ }^{2}$
}

\begin{abstract}
Resumo
Este artigo propõe-se a analisar a perspectiva constitucional da educação, enquanto promotora de desenvolvimento pessoal, do exercício da cidadania e da qualificação para o trabalho. No entanto, o ensino jurídico atual, baseado numa lógica cartesiana, positivista, fragmentada e descontextualizada não tem se mostrado apto para o alcance desses objetivos. A transdisciplinaridade pode oferecer subsídios para a alteração desse quadro, uma vez que promove uma visão ampla, crítica e holística do objeto de estudo. Utilizou-se o método de abordagem dedutivo e a pesquisa dogmático-jurídica de natureza bibliográfica, por meio da consulta de obras e documentos.
\end{abstract}

Palavras-chave: Educação; Constituição Federal de 1988; Transdisciplinaridade; Ensino jurídico; Libertação; Cidadania.

\section{THE CONSTITUTIONAL CONTENT OF EDUCATION: CONTRIBUTIONS OF TRANSDISCIPLINARITY TO A LEGAL EDUCATION AND CITIZEN PROMOTER}

\begin{abstract}
This article proposes to analyze the constitutional perspective of education, as a promoter of personal development, the exercise of citizenship and qualification for labor. However, current legal education, based on a Cartesian, positivist, fragmented and decontextualized logic, has not been shown to be suitable for achieving these objectives. Transdisciplinarity can provide support for changing this framework, since it promotes a broad, critical and holistic view of the object of study. The method of deductive approach and the dogmatic-juridical research of bibliographical nature were used, through the consultation of works and documents.
\end{abstract}

Keywords: Education; Federal Constitution of 1988; Transdisciplinarity; Legal education; Release; Citizenship.

\footnotetext{
${ }^{1}$ Mestrando em Direito pela Universidade FUMEC. Procurador do Trabalho, do Ministério Público do Trabalho (MPT). Professor universitário. Especialista em Direito Público pela Faculdade de Direito do Vale do Rio Doce (FADIVALE) e em Direitos Humanos e Trabalho pela Escola Superior do Ministério Público da União (ESMPU).

2 Especialista, Mestre e Doutor em Direito Comercial/Empresarial pela UFMG. Professor Adjunto da Universidade FUMEC $(\mathrm{BH})$.
}

Rev. de Direitos Fundamentais nas Relações do Trabalho, Sociais e Empresariais | e-ISSN: 2525-9903 | Maranhão | v. 3 | n. 2 | p. 23 - 44 | Jul/Dez. 2017. 


\section{INTRODUÇÃO ${ }^{3}$}

A educação traduz um dos mais importantes direitos previstos em favor das pessoas nos documentos internacionais de direitos humanos, tendo a Constituição Federal de 1988, do Brasil, em consonância com esse espírito, previsto a educação como direito social, fundamental e universal.

O problema que se propõe é investigar o conteúdo da educação à luz da Constituição Federal de 1988 e qual o seu papel na promoção da liberdade individual e da cidadania, notadamente porque, quando se fala em educação, a tônica tem sido a sua necessidade para a qualificação para o exercício do trabalho, sem o aprofundamento dos outros aspectos constitucionalmente previstos.

Adotou-se como marco teórico as discussões promovidas por Frederico de Andrade Gabrich no artigo "Transdisciplinaridade no Ensino Jurídico", especificamente na constatação de que o ensino jurídico atual reclama uma visão holística e que leve em consideração os saberes de outros ramos do conhecimento, os quais são atualmente desprezados por um ensino hermético, fragmentado, cartesiano, positivista e anacrônico.

De início, serão tecidas considerações conceituais acerca do termo educação, com posterior análise dos direitos sociais, nos quais se insere o direito à educação. Em tópicos seguintes, o conteúdo da educação na Constituição Federal de 1988 será objeto de análise, bem como se discutirá como o ensino jurídico pode colaborar na promoção da libertação individual e da cidadania, bem como para a eficácia do princípio constitucional fundamental relativo ao direito à educação. Por fim, analisar-se-á como a transdisciplinaridade pode oferecer importantes subsídios para que o ensino jurídico logre concretizar os objetivos constitucionalmente propostos para a educação.

Para o alcance dos objetivos propostos, utilizou-se o método de abordagem dedutivo e a pesquisa dogmático-jurídica de natureza bibliográfica, por meio da consulta de obras e documentos.

\footnotetext{
${ }^{3}$ Os autores agradecem o apoio recebido da Fundação de Amparo à Pesquisa do Estado de Minas Gerais FAPEMIG e da Universidade Fumec, para realização da pesquisa e divulgação dos seus resultados.
} 


\section{UM CONCEITO PARA EDUCAÇÃO}

O tema educação no Brasil tem sido alvo de inúmeros e abalizados debates entre os estudiosos, não havendo discordâncias de que ela deve figurar como prioridade nas agendas governamentais, juntamente com a promoção e a garantia da saúde a todas as pessoas.

Nesse sentido, Gilmar Ferreira Mendes observa que "dentre os direitos sociais, o direito à educação tem assumido importância predominante para a concretização dos valores tutelados pela Constituição e, principalmente, para a construção de patamar mínimo de dignidade para os cidadãos" (MENDES, 2014, p. 675).

Mas o que vem a ser educação? Como se compreender o seu conteúdo?

Com efeito, o termo educação pode ser utilizado com várias acepções, tangenciando desde o viés de formação e de desenvolvimento intelectual da pessoa até o aspecto de tratamento cortês nas relações interpessoais.

No entanto, no que diz respeito ao tema tratado neste artigo, vale trazer à colação alguns conceitos da educação enquanto meio de formação e de desenvolvimento físico, intelectual e moral do indivíduo.

Sem a pretensão de esgotar a significação de um termo tão amplo e plurissignificativo, como é a educação, tem-se por relevante traçar uma análise conceitual da terminologia, ainda que perfunctória, como forma de melhor compreender-lhe o conteúdo.

J. M. Othon Sidou (1995, p. 296) conceitua educação da seguinte forma: "S.f. (Lat. Educatio) Formação do espírito de uma pessoa, visando ao seu desenvolvimento físico, intelectual e moral, e cuja promoção é direito de todos e dever do Estado e da família. CF, arts. 205, 208, 214".

Ressai do conceito acima a qualificação formacional ofertada pela educação à pessoa, para que seja promovido o seu desenvolvimento pleno, ou seja, físico, intelectual e moral.

Por seu turno, destacando o aspecto dinâmico e continuativo da educação, enquanto processo, bem como o seu viés de civilidade, Antônio Houaiss (2008, p. 269) traz o seguinte conceito: "S.f. 1 processo para o desenvolvimento físico, intelectual e moral de um ser humano 2 conjunto dos métodos empregados nesse processo; instrução, ensino 3 desenvolvimento metódico (de faculdade, sentido, órgão etc) 4 civilidade, polidez".

Rev. de Direitos Fundamentais nas Relações do Trabalho, Sociais e Empresariais | e-ISSN: 2525-9903 | Maranhão | v. 3 | n. 2 | 
O mesmo Antônio Houaiss (2008, p. 296) ensina que educar é "1 fornecer a (alguém) os cuidados necessários ao pleno desenvolvimento físico, intelectual e moral 2 transmitir saber a; ensinar, instruir 3 fazer (o animal) obedecer, domar. 4 buscar atingir alto grau de desenvolvimento; aperfeiçoar-se".

Portanto, para fins do presente estudo, a educação pode ser entendida como um processo de formação do espírito da pessoa, com o objetivo de promover-lhe o desenvolvimento físico, intelectual e moral, por meio de métodos de instrução e de ensino, e mediante desenvolvimento metódico na transmissão do saber e do ensino.

Enquanto direito, a educação deve ser promovida em favor de todos (universalidade) pelo Estado e pela família, cabendo a esta de forma precípua a sua realização quanto aos aspectos da moral e da civilidade.

\section{OS DIREITO SOCIAIS NA HISTÓRIA. A EDUCAÇÃO COMO DIREITO HUMANO NOS DOCUMENTOS INTERNACIONAIS}

No plano histórico, analisa-se a gestação dos direitos humanos sob a perspectiva de gerações ou dimensões, levando-se em consideração o aspecto de cumulatividade desses direitos ao longo do tempo, com o incremento do rol de garantias.

Os chamados direitos de primeira dimensão foram forjados com a pretensão de romper com os regimes absolutistas, no século XVIII, marcando a passagem do Estado autoritário para um Estado de Direito (LENZA, 2014). Esses direitos, impregnados do valor liberdade, impõem um não fazer em face do Estado (absenteísmo estatal), como forma de proteger o indivíduo dos abusos e arbitrariedades então praticados pelos soberanos, detentores que eram de um poder ilimitado e incontrastável.

Não obstante, tendo-se como palco histórico a Revolução Industrial europeia, a partir do século XIX, em meio a péssimas condições de trabalho e de estado de miserabilidade no qual muitas pessoas se encontravam imersas, deflagraram-se movimentos de reivindicação trabalhista na Inglaterra e na França, em busca de normas de assistência social e de melhoria nas condições de vida dos necessitados (LENZA, 2014). Verificou-se que a simples abstenção do Estado para proteger o indivíduo dos abusos não fora suficiente para se alcançar efetividade

Rev. de Direitos Fundamentais nas Relações do Trabalho, Sociais e Empresariais | e-ISSN: 2525-9903 | Maranhão | v. 3 | n. 2 | p. $23-44$ | Jul/Dez. 2017. 
na promoção da dignidade da pessoa humana, sustentáculo de todo o sistema de proteção dos direitos humanos.

Se os direitos de primeira dimensão objetivavam garantia a igualdade formal, impunhase a concretização da igualdade material ou substancial por meio dos direitos de segunda dimensão, chamados de direitos sociais, culturais e econômicos, os quais, para tanto, exigem do Estado a oferta de prestações positivas em favor daqueles que delas necessitam.

A Constituição Mexicana, de 19187, e a Constituição de Weimar, de 1919, na Alemanha, foram as primeiras constituições a trazerem em seu corpo textual direitos sociais (LENZA, 2014), imprimindo-lhes, assim, status constitucional, e, por consequência, consolidando uma maior garantia contra modificações levadas a efeito por normas de hierarquia inferior.

Ainda na perspectiva de dimensões, têm-se os direitos humanos de terceira dimensão, que são os transindividuais, ligados à proteção do meio ambiente, aos direitos do consumidor e ao desenvolvimento, permeados de alto valor de humanismo e de solidariedade (LENZA, 2014).

$\mathrm{Na}$ análise de Costa Douzinas,

\begin{abstract}
Os direitos humanos diversificaram-se de direitos civis e políticos, ou "negativos", da "primeira geração", associados ao liberalismo, para direitos econômicos, sociais e culturais, ou "positivos", da "segunda geração", associados à tradição socialista, e, finalmente, para direitos de grupos e de soberania nacional da "terceira geração", associados ao processo de descolonização. A primeira geração, ou direitos "azuis", é simbolizada pela liberdade individual; a segunda, ou direitos "vermelhos", por reivindicações de igualdade e de garantias de um padrão de vida decente, ao passo que a terceira, ou direitos "verdes", pelo direito à autodeterminação e, tardiamente, pela proteção do meio ambiente" (DOUZINAS, 2009, p. 127).
\end{abstract}

No que diz respeito à educação, é importante registrar que o tema recebeu tratamento especial na Declaração Universal dos Direitos Humanos, da Organização das Nações Unidas (ONU), cujo artigo $26^{\circ}$ assim dispõe:

Artigo $26^{\circ} 1$. Toda a pessoa tem direito à educação. A educação deve ser gratuita, pelo menos a correspondente ao ensino elementar fundamental. O ensino elementar é obrigatório. O ensino técnico e profissional dever ser generalizado; o acesso aos estudos superiores deve estar aberto a todos em plena igualdade, em função do seu mérito.

Rev. de Direitos Fundamentais nas Relações do Trabalho, Sociais e Empresariais | e-ISSN: 2525-9903 | Maranhão | v. 3 | n. 2 | 
2. A educação deve visar à plena expansão da personalidade humana e ao reforço dos direitos do Homem e das liberdades fundamentais e deve favorecer a compreensão, a tolerância e a amizade entre todas as nações e todos os grupos raciais ou religiosos, bem como o desenvolvimento das atividades das Nações Unidas para a manutenção da paz.

3. Aos pais pertence a prioridade do direito de escolher o género de educação a dar aos filhos (ONU, 1948).

Ainda no âmbito da Organização das Nações Unidas, a educação foi tema do Pacto Internacional dos Direitos Econômicos Sociais e Culturais, que em seu artigo $13^{\circ}$ dispõe:

\begin{abstract}
Artigo 13. ${ }^{\circ}$ 1. Os Estados Partes no presente Pacto reconhecem o direito de toda a pessoa à educação. Concordam que a educação deve visar ao pleno desenvolvimento da personalidade humana e do sentido da sua dignidade e reforçar o respeito pelos direitos do homem e das liberdades fundamentais. Concordam também que a educação deve habilitar toda a pessoa a desempenhar um papel útil numa sociedade livre, promover compreensão, tolerância e amizade entre todas as nações e grupos, raciais, étnicos e religiosos, e favorecer as atividades das Nações Unidas para a conservação da paz [...] (ONU, 1966).
\end{abstract}

Portanto, os direitos sociais, entre os quais se insere a educação, possuem previsão em documentos internacionais de proteção dos direitos humanos, traduzindo os chamados direitos de segunda dimensão, pelo que demandam prestações positivas do Estado para a sua concretização, com o objetivo de se promover uma igualdade efetiva e não meramente formal entre as pessoas.

\title{
3 O DIREITO À EDUCAÇÃO NA CONSTITUIÇÃO FEDERAL DE 1988 (CF/88)
}

A Constituição Federal de 1988 (CF/88), instituidora de uma nova ordem no Brasil, inspirou-se no espírito humanista que marcou a edição da Declaração Universal dos Direitos Humanos, do Pacto Internacional de Direitos Civis e Políticos, do Pacto Internacional de Direitos Econômicos, Sociais e Culturais, todos da Organização das Nações Unidas (ONU), entre outros documentos internacionais fundados na centralidade da pessoa humana e na sua dignidade como fio condutor de todo o ordenamento jurídico.

Já no preâmbulo, o Constituinte originário fez constar que o Estado Democrático inaugurado no Brasil seria destinado a assegurar o exercício dos direitos sociais e individuais, a liberdade, a segurança, o bem-estar, o desenvolvimento, a igualdade e a justiça como valores supremos.

Rev. de Direitos Fundamentais nas Relações do Trabalho, Sociais e Empresariais | e-ISSN: 2525-9903 | Maranhão | v. 3 | n. 2 | 
No seu artigo $1^{\circ}$, a Constituição Federal prevê os fundamentos da República Federativa do Brasil, com destaque para a dignidade da pessoa humana (BRASIL, 1988) ${ }^{4}$.

A propósito da importância dos fundamentos constitucionais e notadamente da dignidade da pessoa humana como um deles, Max Emiliano da Silva Sena observa que:

[...] quando se fala em fundamento leva-se em consideração a estrutura ou as bases de
todo o edifício estatal, construído a partir da nova Constituição, e não só isso, mas
também se põe em relevo a própria razão de ser e de existir do Estado inaugurado, de
molde que, atingido um dos fundamentos erigidos, põe-se em risco não apenas o
direito agasalhado pelo fundamento, mas a própria existência do Estado.
Ao erigir a dignidade da pessoa humana à condição de fundamento do Estado
Democrático de Direito, a Constituição Federal de 1988 diz de forma firme, segura e
eloquente que no Estado brasileiro a pessoa humana desfruta de especial destaque,
sendo o centro de todo o sistema, de molde que todo o ordenamento jurídico, todos os
órgãos de governo, todas as ações políticas e todas as condutas particulares devem
respeito à pessoa humana (SENA, 2016).

No que tange aos direitos sociais, o artigo art. $6^{\circ}$ da $\mathrm{CF} / 88$ dispõe que: "São direitos sociais a educação, a saúde, a alimentação, o trabalho, a moradia, o lazer, a segurança, a previdência social, a proteção à maternidade e à infância, a assistência aos desamparados, na forma desta Constituição" (BRASIL, 1988).

Além de prever a educação como direito social no artigo $6^{\circ}$, a Constituição Federal de 1988, em seu artigo 205, dispõe: “A educação, direito de todos e dever do Estado e da família, será promovida e incentivada com a colaboração da sociedade, visando ao pleno desenvolvimento da pessoa, seu preparo para o exercício da cidadania e sua qualificação para o trabalho" (BRASIL, 1988).

Comentando a universalidade e a fundamentalidade da educação, bem como a necessidade do aparelhamento do Estado para a sua promoção, José Afonso da Silva leciona:

${ }^{4}$ Artigo $1^{\circ}$ da Constituição Federal de 1988: “Art. $1^{\circ}$ A República Federativa do Brasil, formada pela união indissolúvel dos Estados e Municípios e do Distrito Federal, constitui-se em Estado Democrático de Direito e tem como fundamentos:

I - a soberania;

II - a cidadania

III - a dignidade da pessoa humana;

IV - os valores sociais do trabalho e da livre iniciativa;

V - o pluralismo político".

Rev. de Direitos Fundamentais nas Relações do Trabalho, Sociais e Empresariais | e-ISSN: 2525-9903 | Maranhão | v. 3 | n. 2 | 
$\mathrm{O}$ art. 205 contém uma declaração fundamental que, combinada com o art. $6^{\circ}$, eleva a educação ao nível dos direitos fundamentais do homem. Aí se afirma que a educação é direito de todos, com o que esse direito é informado pelo princípio da universalidade. Realça-lhe o valor jurídico, por um lado, a cláusula - a educação é dever do Estado e da família -, constante do mesmo artigo, que contempla a situação jurídica subjetiva, ao explicitar o titular do dever, da obrigação, contraposto àquele direito. Vale dizer: todos têm o direito à educação e o Estado tem o dever de prestá-la, assim como a família. A norma, assim explicitada - "a educação, direito de todos e dever do Estado e família [...]" (arts. 205 e 227) -, significa, em primeiro lugar, que o Estado tem que aparelhar-se para fornecer, a todos, os serviços educacionais, isto é, oferecer ensino, de acordo com os princípios estatuídos na Constituição (art. 206); que ele tem que ampliar cada vez mais as possibilidades de que todos venham a exercer igualmente esse direito; e, em segundo lugar, que todas as normas da Constituição, sobre educação e ensino, hão que ser interpretadas em função daquela declaração e no sentido de sua plena e efetiva realização" (SILVA, 2008, p. 312-313).

Na linha das lições de José Afonso da Silva, vale registrar que o direito social à educação reveste-se de natureza jurídica subjetiva, passível, portanto, de exigibilidade contra o Estado, em casos de omissão quanto à sua oferta nos moldes garantidos pela Constituição Federal.

Sobre a temática, Gilmar Ferreira Mendes consigna que:

São relevantes as controvérsias já submetidas ao STF sobre o direito à educação. Nesses casos, o Supremo tem se deparado com o problema da interferência do Judiciário na elaboração de políticas públicas, bem como com a necessidade de garantir direitos fundamentais sociais. Nas hipóteses em que se requer o acesso à creche, em virtude da insuficiência das vagas disponibilizadas pelo Poder Público, "a jurisprudência do STF firmou-se no sentido da existência de direito público subjetivo de crianças até cinco anos de idade ao atendimento em creches e pré-escolas. (...) também consolidou o entendimento de que é possível a intervenção do Poder Judiciário visando à efetivação daquele direito constitucional". De acordo com o art. 208, IV, da Constituição, com redação dada pela Emenda Constitucional n. 53, de 2006, deve ser assegurada a educação infantil em creche e pré-escola às crianças de até 5 anos (MENDES, 2014, p. 677).

Assim, a Constituição Federal de 1988 prevê a educação como direito fundamental universal, ou seja, direito de todos, devendo ser garantida pelo Estado e pela família, visando ao pleno desenvolvimento da pessoa, ao seu preparo para o exercício da cidadania e à sua qualificação para o trabalho.

\section{O CONTÉUDO DA EDUCAÇÃO NA PERSPECTIVA CONSTITUCIONAL}


Examinada a natureza fundamental e universal do direito à educação, bem como a sua exigibilidade enquanto direito público subjetivo, revela-se necessário perquirir acerca do seu conteúdo na perspectiva constitucional.

Da leitura do artigo 205 da CF/88 ressai que a oferta da educação possui os seguintes escopos: a) pleno desenvolvimento da pessoa; b) preparo da pessoa para o exercício da cidadania; c) a sua qualificação para o trabalho (BRASIL, 1988).

Comentando o referido artigo da Constituição Federal, Bernardina F. F. Abrão aduz que:

\begin{abstract}
A educação, em seu conceito amplo, é essencial ao pleno desenvolvimento humano, como pressuposto básico ao reconhecimento dos direitos, dos deveres, das responsabilidades, em todos os setores, perante qualquer ordem social estabelecida. Por meio dela a pessoa transforma-se, cria valores, qualifica-se para o trabalho e exerce e instrumentaliza sua cidadania (ABRÃO, 2014, p. 1057).
\end{abstract}

A proposta deste trabalho reside na busca de respostas para as seguintes indagações, adotadas como tema-problema: Qual o verdadeiro conteúdo constitucional do direito à educação? Qual o papel da educação à luz da CF/88? Qual o reflexo da educação em termos de promoção da liberdade e da cidadania? Como o ensino jurídico pode promover a libertação individual e o exercício da cidadania? Quais os subsídios que podem ser ofertados pela transdisciplinaridade para o alcance dos objetivos constitucionais para a educação?

A justificativa para esses questionamentos encontra fundamento na análise das atuais metodologias e métodos de ensino adotados nas escolas, notadamente nas faculdades de Direito, os quais muitas vezes se mostram inaptos e inócuos para o alcance dos objetivos insculpidos na Constituição Federal.

A seguir serão analisados os objetivos da educação, os quais revelam o seu conteúdo e a sua significação na perspectiva constitucional, de molde a se lançar as bases para a realização de reflexões acerca do atual cenário do ensino jurídico, com a apresentação de propostas que poderão ser úteis para que se logre atingir as reais finalidades da educação, enquanto meio de libertação individual e de promoção da cidadania, bem como os subsídios ofertados pela transdisciplinaridade para o alcance desse desiderato.

\title{
4.1 O PLENO DESENVOLVIMENTO DA PESSOA
}

Rev. de Direitos Fundamentais nas Relações do Trabalho, Sociais e Empresariais | e-ISSN: 2525-9903 | Maranhão | v. 3 | n. 2 | p. 23 - 44 | Jul/Dez. 2017. 
É lugar comum aconselhar-se uma pessoa a estudar para que obtenha qualificação e formação intelectuais que lhe garantam melhores condições para a inserção no mercado de trabalho.

Não obstante, o primeiro objetivo proposto para a educação sob a perspectiva constitucional centra-se na promoção do pleno desenvolvimento a pessoa.

A par do conceito trazido por J. M. Othon Sidou, tem-se que a educação liga-se à formação do espírito de uma pessoa, tendo como objetivo promover-lhe o desenvolvimento físico, intelectual e moral (SIDOU, 1995).

A questão central, aqui, reside na promoção do desenvolvimento do indivíduo, enquanto pessoa, como forma de lhe proporcionar condições para uma existência feliz, consciente e dotada de autonomia, ou seja, garantir-lhe liberdade em sua acepção plena, pondo-o a salvo da alienação, da domesticação e da dominação intelectual.

O desenvolvimento liga-se à ideia de um processo continuado no qual cada pessoa terá condições de se sentir bem consigo mesma, de forma racional, livre e autônoma, ainda que, logrando uma formação acadêmica, opte por não exercer a profissão correlata.

\subsection{PREPARO PARA O EXERCÍCIO DA CIDADANIA}

O segundo objetivo proposto para a educação sob a viés constitucional é preparar a pessoa para o exercício da cidadania.

A propósito, o que vem a ser cidadania?

Marcus Cláudio Acquaviva (2010, p. 172) consigna que cidadania é o "vínculo político que liga o indivíduo ao Estado e que lhe atribui direitos e deveres de natureza política”.

Segundo Maria Helena Diniz (2010, p. 115), cidadania por ser conceituada como “qualidade ou estado de cidadão; vínculo político que gera para o nacional deveres e direitos

políticos, uma vez que o liga ao Estado. É a qualidade de cidadão relativa ao exercício das prerrogativas políticas outorgadas pela Constituição de um Estado democrático”.

J. M. Othon Sidou (1995, p. 133) traz o seguinte conceito para cidadania: "Capacidade política que tem o indivíduo para influir na formação do governo, seja na forma ativa, pelo 
exercício do sufrágio, seja na condição passiva, como exercente de funções eletivas ou a elas candidato".

Por seu turno, Gabriela Neves Delgado tece considerações acerca do conceito alargado e atual de cidadania, para além do simples exercício do sufrágio universal:

Já a cidadania, em sentido amplo e contemporâneo, típica de um Estado Democrático de Direito, pode ser conceituada como a aptidão do indivíduo em adquirir direitos, prerrogativas e proteções da ordem jurídica, aptos a qualificá-lo como igual a seus semelhantes no contexto da sociedade local, regional ou internacional (DELGADO, 2006, p. 52)

Dessarte, a cidadania, enquanto vínculo político entre o Estado e o cidadão, confere a este deveres e direitos quanto ao exercício de prerrogativas constitucionalmente previstas, como o exercício voto, de funções públicas, entre outras, e, além disso, qualifica-o de forma igualitária aos seus semelhantes, no âmbito social no qual se encontra inserido.

A respeito da relação entre educação e cidadania, Bernardina F. F. Abrão arremata

E cidadania vem a ser não só conhecimento, mas a busca das formas de instrumentalização dos direitos, dos deveres, das obrigações, das responsabilidades, das garantias dadas pela Constituição, dos direitos políticos, da seguridade social, da educação, da cultura, das atribuições dos Poderes Executivo, Legislativo e Judiciário, entre tantas outras coisas (ABRÃ̃O, 2014, p. 1057).

Seguramente, sem educação não há que se falar em liberdade, em autonomia ou no exercício pleno da cidadania.

A partir dessas análises, resta claro que somente por meio da educação será possível o alcance da formação intelectual do indivíduo, para que tenha condições de exercer de forma livre, consciente e plena a cidadania, em sua acepção ampla e contemporânea.

\subsection{QUALIFICAÇÃO PARA O TRABALHO}

Como terceiro objetivo a ser alcançado pela educação, a Constituição Federal prevê a promoção da qualificação da pessoa para o exercício do trabalho.

O tema referente ao trabalho recebeu tratamento especial na $\mathrm{CF} / 88$, na medida em que consubstancia um dos principais instrumentos para a concretização dos objetivos estabelecidos 
em seu artigo $3^{\circ}$, consistentes na construção de uma sociedade livre, justa e solidária; na garantia do desenvolvimento nacional; na erradicação da pobreza e da marginalização e na redução das desigualdades sociais e regionais; e na promoção do bem de todos, sem preconceitos de origem, raça, sexo, cor, idade e quaisquer outras formas de discriminação (BRASIL, 1988) ${ }^{5}$.

Como corolário do valor liberdade, que permeia todo o texto constitucional, no que se refere ao trabalho, a $\mathrm{CF} / 88$, no artigo $5^{\circ}$, inciso XIII, estabelece que "é livre o exercício de qualquer trabalho, ofício ou profissão, atendidas as qualificações profissionais que a lei estabelecer" (BRASIL, 1988).

Percebe-se, claramente, que o livre exercício do trabalho encontra-se imbricado com a qualificação profissional, que somente poderá se auferida por meio da educação, uma vez que, sem educação o indivíduo não receberá a formação necessária para que, livremente, possa proceder às escolhas consentâneas às suas aspirações profissionais.

Sem educação não haverá qualificação adequada e, por consequência, não se poderá falar em liberdade no exercício de qualquer trabalho, ofício ou profissão, do que ressai a importância da educação para a qualificação e o livre exercício do trabalho. Pelo contrário, sem educação que o emancipe e o revista de liberdade e autonomia, o indivíduo acabará por se submeter a condições indignas e alienantes de trabalho, em frontal violação à dignidade da pessoa humana e aos valores sociais do trabalho.

\section{SUBSÍDIOS DO ENSINO JURÍDICO PARA O ALCANCE DOS OBJETIVOS CONSTITUCIONAIS DA EDUCAÇÃOO}

A educação, caso não seja ofertada de modo a despertar uma autêntica conscientização do indivíduo, enquanto ser consciente, autônomo e racional, poderá servir de instrumento de domesticação, dissociando-se, portanto, da proposta prevista na Constituição Federal de 1988,

\footnotetext{
${ }^{5}$ Artigo $3^{\circ}$, da Constituição Federal de 1988:

“Art. $3^{\circ}$ Constituem objetivos fundamentais da República Federativa do Brasil:

I - construir uma sociedade livre, justa e solidária;

II - garantir o desenvolvimento nacional;

III - erradicar a pobreza e a marginalização e reduzir as desigualdades sociais e regionais;

IV - promover o bem de todos, sem preconceitos de origem, raça, sexo, cor, idade e quaisquer outras formas de discriminação".
} 
consistente na promoção do pleno desenvolvimento da pessoa, do seu preparo para o exercício da cidadania e da sua qualificação para o trabalho.

No que se refere ao ensino jurídico, o que de certa forma também se aplica aos demais ramos do conhecimento, nota-se que as metodologias utilizadas nas salas de aulas das faculdades são anacrônicas, obsoletas, alienantes e inaptas para atingimento das aspirações pessoais e sociais, e das demandas do mercado.

Nesse sentido, Frederico de Andrade Gabrich observa que:

\begin{abstract}
O ensino do Direito precisa evoluir na mesma medida das evoluções ocorridas desde antes do início formal do Século XXI e que perduram até os dias atuais. A realidade social, econômica, política e cultural da maioria dos países e o interesse dos alunos dos cursos de graduação - inclusive em Direito - mudaram completa e radicalmente nos últimos 25 anos. Todavia, os processos de formação do conhecimento e, principalmente, as metodologias de ensino, de avaliação e até de pesquisa científica, especialmente no âmbito jurídico, não evoluíram na mesma proporção (GABRICH, 2013, p. 2).
\end{abstract}

O curso de Direito, de uma forma bastante peculiar, pode proporcionar ao acadêmico uma visão mais holística do contexto social, na medida em que todas as relações sociais, de uma forma ou de outra, encontram-se regidas por normas jurídicas. Dessa forma, o ensino jurídico, para além de qualificar a pessoa para o exercício de várias funções que demandam o diploma de bacharel em Direito, pode lograr o atingimento dos objetivos propostos pela Constituição Federal de 1988, auxiliado de forma decisiva no desenvolvimento pessoal do indivíduo e na formação de um cidadão preparado, livre, dotado de autonomia e consciente do seu papel na sociedade em que vive.

Por outro lado, um curso nos moldes atuais, sem visão holística e crítica da realidade, pode acabar por plasmar pessoas meramente assimiladoras de conceitos, sem espírito crítico da realidade, sem consciência, sem liberdade em sua acepção plena, dependentes, manipuláveis, passivas e facilmente domesticáveis pelo dogmatismo imposto.

A educação em geral, e a educação jurídica em especial, pode ser manejada como estratégia de domesticação ou de libertação, a depender das metodologias que forem utilizadas no ensino.

Com efeito, na dicção de Paulo Freire, 
[...] o processo de alfabetização política - como o processo linguístico - pode ser uma prática para a "domesticação dos homens", ou uma prática para sua libertação. No primeiro caso, a prática da conscientização não é possível em absoluto, enquanto no segundo caso o processo é, em si mesmo, conscientização. Daí uma ação desumanizante, de um lado, e um esforço de humanização, de outro (FREIRE, 1980, p. 27).

Considerando que "o tema fundamental de nossa época é o da dominação, que supõe seu reverso, o tema da libertação, como objetivo que deve ser alcançado" (FREIRE, 1980, p. $30)$.

Para a promoção dessa libertação, demanda-se por uma educação de conscientização, que leve em consideração o estudante enquanto ser ativo, consciente, crítico e inserido no processo educacional, ou que, de alguma forma, o instigue a se envolver nesse processo, não deixando de considerar, ainda, as seus aspirações e potencialidades.

Nesse sentido, Paulo Freire (1976, p. 25) pontua que: “Ao ouvir pela primeira vez a palavra conscientização, percebi imediatamente a profundida de seu significado, porque estou absolutamente convencido de que a educação, como prática da liberdade, é um ato de conhecimento, uma aproximação crítica da realidade".

$\mathrm{O}$ ensino jurídico atual baseia-se predominantemente em aulas expositivas, com a adoção de metodologias instrucionistas e repetidoras de textos normativos, que desprezam a inserção do estudante no processo de construção do conhecimento, não levando em consideração o seu papel de agente crítico e consciente de seu tempo.

Na metodologia instrucionsita, segundo Mizukami,

[...] atribui-se ao sujeito um papel irrelevante na elaboração e aquisição do conhecimento. Ao indivíduo que está adquirindo o conhecimento compete memorizar e definir, enunciados de leis, sínteses e resumos que lhes são oferecidos no processo de educação formal a partir de um esquema atomístico (MIZUKAMI, 1986. p.11)

Oportunas, ainda, as palavras de Paulo Freire:

Uma das características do homem é que somente ele é homem. Somente ele é capaz de tomar distância frente ao mundo. Somente o homem pode distanciar-se do objeto para admirá-lo. Objetivando ou admirando - admirar se toma aqui no sentido filosófico - os homens são capazes de agir conscientemente sobre a realidade objetivada. É precisamente isto, a "práxis humana", a unidade indissolúvel entre minha ação e minha reflexão sobre o mundo" (FREIRE, 1980, p. 25-26). 
A promoção da conscientização que leve à libertação do indivíduo revela-se necessária para que logre implementar uma educação capaz de propiciar o desenvolvimento pessoal do indivíduo e o seu preparo para o exercício da cidadania, bem como a sua qualificação para a escolha e o desempenho, com liberdade, de uma profissão que, efetivamente, garanta-lhe as condições favoráveis e adequadas para a sua afirmação individual e coletiva.

Novamente, Paulo Freire ensina que:

\begin{abstract}
A conscientização não está baseada sobre a consciência, de um lado, e o mundo, de outro; por outra parte, não pretende uma separação. Ao contrário, está baseada na relação consciência-mundo. [...] A conscientização, como atitude crítica dos homens na história, não terminará jamais. Se os homens, como seres que atuam, continuam aderindo a um mundo "feito", ver-se-ão submersos numa nova obscuridade. [...] Assim, a vocação do homem é a de ser sujeito e não objeto. Pela ausência de uma análise do meio cultural, corre-se o perigo de realizar uma educação pré-fabricada, portanto, inoperante, que não está adaptada ao homem concreto a que se destina” " (FREIRE, 19870, p. 26-27, 34).
\end{abstract}

Assim, indubitável que o ensino jurídico revela-se como importante fonte de subsídios para o atingimento dos objetivos propostos para a educação na Constituição Federal de 1988, ressalvando-se, no entanto, a necessidade de superação do modelo atual de ensino, marcadamente instrucionista e que não leva o estudante à conscientização acerca do mundo em que vive, e nem tampouco o considera como parte do processo educacional.

\title{
6 A TRANSDISCIPLINARIDADE APLICADA AO ENSINO JURÍDICO
}

$\mathrm{Na}$ atualidade, com raras exceções, o ensino jurídico ministrado nas salas de aula parte do pressuposto de que o professor é o detentor único e supremo do conhecimento, o que deflui da desconsideração do aluno no processo do conhecimento e da utilização preponderante, senão única, da metodologia instrucionista, mediante aulas expositivas. Nesse cenário, "a educação padece da doença da narração" (FREIRE, 1980, p. 78).

O distanciamento entre o ensino oferecido em sala de aula e as necessidades atuais acaba por desmotivar o estudante, que se vê a cada aula entulhado com um conteúdo sem significação, ou seja, que em nada acrescenta para o seu desenvolvimento pessoal e para a sua qualificação profissional em um mercado diferente daquele de 20 ou 30 anos atrás. Há a nítida sensação de que o tempo de permanência em sala foi inútil. 
Frederico de Andrade Gabrich observa que:

\begin{abstract}
No âmbito específico do ensino do Direito, é cada vez mais evidente o descompasso entre essas novas realidades sócioculturais vivenciadas no Século XXI, o atual interesse profissional dos alunos dos cursos jurídicos e as metodologias tradicionais de formação do conhecimento, do ensino, da pesquisa e da avaliação. Isso é facilmente evidenciado pelas experiências dos professores em sala de aula, comprovadas por depoimentos significativos e repetidos, tais como: “...os alunos não reagem às aulas e não demonstram interesse...", “...são poucos os alunos que realmente estudam os tópicos da disciplina independentemente da realização de provas...", "os alunos não leem nada" etc" (GABRICH, 2013, p. 4).
\end{abstract}

O ensino fragmentado, superespecializado, anacrônico, descontextualizado e sem significação pode ser facilmente constatado quando:

O professor fala da realidade como se esta fosse sem movimento, separada em compartimentos e previsível; ou então, fala de um tema estranho à experiência existencial dos estudantes: neste caso sua tarefa é "encher" os alunos do conteúdo da narração, conteúdo alheio à realidade, separado da totalidade que a gerou e poderia dar-lhe sentido" (FREIRE, 1980, p. 78-79).

A metodologia instrucionista, embora seja de uso aconselhável em relação a alguns conteúdos específicos, quando usada de forma exclusiva ou preponderante, como vem ocorrendo, acaba por transformar o aluno em mero depósito de conceitos e mais conceitos, uma vez que não lhe é dado participar do processo, de tecer considerações críticas e de trazer à discussão elementos de outras áreas do conhecimento que possam ter conexão com o tema tratado na aula.

Dessa forma, segundo Paulo Freire, "a educação passa a ser "o ato de depositar", no qual os alunos são os depósitos e o professor aquele que deposita. Em lugar de comunicar, o professor dá comunicados que os alunos recebem pacientemente, aprendem e repetem. É a concepção "acumulativa” da educação (concepção bancária)" (FREIRE, 1980 p. 79).

Partir do pressuposto de que o aluno ignora por completo o conteúdo, que não possua nenhum conhecimento, ainda que de outra área do saber e que possa ter alguma correlação com o tema exposto, ou mesmo deixar de promover o seu envolvimento na construção do conhecimento, "é característica de uma ideologia de opressão. É uma negação da educação e do conhecimento como processo de procura" (FREIRE, 1980, p. 79).

Portanto, a essa altura é possível perceber que o cenário atual do ensino jurídico não promove libertação e desenvolvimento pessoal, nem conscientização apta ao pleno exercício da 
cidadania, e nem tampouco uma qualificação profissional que atenda aos reclamos do mercado atual.

Na dicção de Frederico de Andrade Gabrich, o modelo mental de construção e transmissão do conhecimento demanda mudanças, para o que a transdisciplinaridade pode oferecer importante contribuição. Segundo o autor,

É necessária uma mudança significativa na forma de pensar, de ensinar, de pesquisar e de avaliar, para que os anseios, as necessidades e as demandas dos alunos e dos mercados profissionais sejam atendidas plenamente pelo ensino universitário. Nesse contexto, a transdisciplinaridade significa não apenas um caminho de redenção do ensino, da pesquisa e da extensão universitária, mas, também, um processo importante de formulação de ideias inovadoras e transformadoras, demandadas constantemente neste novo tempo pelas pessoas (especialmente discentes dos cursos de graduação em Direito), pelas empresas, pelas instituições e pelas nações” (GABRICH, 2013, p. 2).

O ensino jurídico permeia-se de dogmatismo, da exigência de assimilação racional de conceitos e mais conceitos, mediante a adoção de matrizes curriculares recheadas de disciplinas muitas vezes herméticas e que não se conectam com outras do mesmo curso e nem com as necessidades da vida real.

O modo de pensar essencialmente cartesiano, em que pese ser a tônica em vários ramos do saber, ganha uma conotação marcante no Direito, por se prender em demasia às tradições, ao passado cultural e a um dogmatismo com a pretensão de imunidade à análise crítica, que o torna hermético, exclusivista, anacrônico e muitas vezes impermeável aos demais saberes.

Por consequência, essas características plasmaram ao longo do tempo professores e profissionais resistentes às mudanças, mesmo num contexto de um mundo diferente e que reclama posturas evoluídas e consentâneas com a nova realidade, em termos de relações sociais, de acesso às informações, de tecnologias, de formas de trabalho de modos de pensar e de viver.

Os meios de aprendizagem normalmente utilizados nas escolas são a multidisciplinaridade, a pluridisciplinaridade e a interdisciplinaridade.

$\mathrm{Na}$ multidisciplinaridade, várias disciplinas são utilizadas para a construção do conhecimento, sem que ocorra, no entanto, uma interconexão entre elas. Inexiste, assim, uma dinâmica colaborativa entre as várias disciplinas estudadas, que acabam por se isolar, sem que se logre uma visão mais ampla do objeto de estudo. 
$\mathrm{Na}$ pluridisciplinaridade, tem-se uma justaposição entre disciplinas assemelhadas, de modo que se observa certa conexão entre elas, embora ainda não se conte com uma autêntica integração e interconexão colaborativas.

Já na interdisciplinaridade é possível vislumbrar a ocorrência de integração colaborativa de métodos de estudo entre duas ou mais disciplinas, para além da justaposição verificada na pluridisciplinaridade.

Não obstante permitir avanço na superação do modelo superespecializado, lógico, cartesiano e linear do ensino, uma vez que proporciona compreensão mais ampla do objeto de estudo, a interdisciplinaridade mantém a individualidade das várias disciplinas.

Por seu turno, a transdisciplinaridade consubstancia um passo a mais em relação à interdisciplinaridade, por romper decisivamente com a concepção racionalista, fragmentada, positivista, cartesiana e isolada do ensino e do objeto de estudo, partindo do pressuposto de que a vida não é linear, antes, pelo contrário, deve ser vista como um todo, com as suas multifacetárias visões, mas jamais de forma estanque ou hermética.

Ensina Frederico de Andrade Gabrich que

\begin{abstract}
$\mathrm{Na}$ transdisciplinaridade o pensar e o ensinar pressupõem a importância de todos os modos de conhecimento, de todas as culturas, religiões, ideias e ciências que convivem e se complementam continua e sistematicamente em vários níveis de realidade. Reconhecer essa situação pode ser extremamente difícil para os profissionais do direito, a começar pelos professores e pela lógica acadêmica ainda dominante, mas é fundamental para a adoção da análise holística, completa e total que caracteriza a transdisciplinaridade. Dessa maneira, o ensino jurídico transdisciplinar precisa reconhecer a existência, a validade e a eficácia normativa de princípios e regras estabelecidas por ordenamentos normativos paralelos ao ordenamento jurídico, que são tão ou mais importantes para determinar a paz social, a prevenção e/ou a solução de conflitos, e a estruturação jurídica dos objetivos das vidas das pessoas em seu dia a dia, tais com os ordenamentos moral, ético, econômico, cultural e social (GABRICH, 2013, p. 13).
\end{abstract}

À luz da transdisciplinaridade inexiste supremacia de um ramo do conhecimento sobre o outro, sendo todos os saberes considerados igualmente importantes para a construção de um conhecimento holístico, amplo e crítico, o que vai ao encontro dos objetivos propostos pela Constituição Federal para a educação, enquanto promotora de bem-estar existencial e social, de exercício responsável da cidadania e de qualificação para um mercado de trabalho que não mais se compadece com profissionais meramente repetidores de conceitos e sem visão do contexto atual da sociedade na qual se encontram inseridos. Com efeito, a dinâmica social atual exige do 
profissional uma conexão permanente com o seu tempo e com a sociedade em que vive, para o que os profissionais gerados nas faculdades não se encontram devidamente preparados a partir dos moldes de ensino atuais.

Segundo Barasab Nicolescu, a transdisciplinaridade pressupõe "respeito àquilo que está ao mesmo tempo entre as disciplinas, através das diferentes disciplinas e além de qualquer disciplina. Seu objetivo é a compreensão do mundo presente, para o qual um dos imperativos é a unidade do conhecimento" (NICOLESCU, 1999, p. 46).

O pensamento transdisciplinar proporciona uma análise ampla e crítica da realidade e leva em consideração o aluno como agente consciente do seu tempo, numa perspectiva de mundo não fragmentado e que exige um pensar holístico, humanizado e humanizante.

Paulo Freire pontua que

\begin{abstract}
"A educação crítica considera que os homens como seres em devir, como seres inacabado, incompletos em uma realidade igualmente inacabada e juntamente com ela. [...] o caráter inacabado dos homens e o caráter evolutivo da realidade exigem que a educação seja uma atividade contínua. A educação é, deste modo, continuamente refeita pela práxis. Para ser, deve chegar a ser" (FREIRE, 1980, p. 81).
\end{abstract}

Portanto, a transdisciplinaridade pode oferecer importantes subsídios para a construção e a transmissão do conhecimento jurídico, mediante um pensar crítico e libertador do pensar hermético, mecanizado, dogmático, positivista, racionalista, cartesiano e alienante, como forma de se concretizar o conteúdo constitucional da educação, qual seja, a promoção do desenvolvimento existencial de cada pessoa, do exercício consciente da cidadania e da qualificação para o trabalho segundo as exigências do atual mercado.

\title{
7 CONCLUSÃO
}

A Constituição Federal de 1988 propõe a educação como meio para a promoção do desenvolvimento pessoal do indivíduo, do exercício da cidadania e da qualificação para o trabalho.

No entanto, o conhecimento jurídico nos moldes atuais não tem logrado alcançar esses objetivos constitucionais da educação, uma vez que se funda em ensino marcadamente 
hermético, fragmentando, cartesiano, positivista e alienante, ministrado mediante metodologias instrucionistas, que desprezam a participação do estudante no processo.

O ensino que efetivamente promova libertação, desenvolvimento, conscientização para o exercício da cidadania e qualificação para o trabalho segundo as exigências do mercado atual deve ocorrer mediante modelos que proporcionem ao indivíduo uma visão crítica, ampla e holística do objeto de estudo, ofertando-lhe conhecimento que possua significação prática e conectada com as suas necessidades e que não se confine na mera assimilação de conceitos sem utilidade. Só assim o direito constitucional à educação será pleno e realmente eficaz.

Para tanto, a transdisciplinaridade pode oferecer importantes subsídios para o alcance dos objetivos propostos para a educação pela Constituição Federal de 1988, na medida em que promove a interconexão colaborativa entre os diversos ramos do conhecimento (científico ou não), partindo do pressuposto de que a vida não é linear e nem estanque, reclamando, assim, uma visão ampla e holística do todo que lhe caracteriza.

O ensino jurídico atual, portanto, deve estar consentâneo com os avanços ocorridos nas várias áreas da vida, para o que precisa se despojar de dogmatismos que em nada colaboram para a promoção de pessoas conscientes, livres e qualificadas para o exercício da cidadania e de trabalho que atenda às demandas do mercado e aos seus anseios pessoais.

\section{REFERÊNCIAS}

ABBAGNANO, Nicola. Dicionário de filosofia. Tradução coordenada e rev. por Alfredo Bosi, com a colaboração de Maurice Cunio et al. 2.ed. São Paulo: Mestre Jou, 1982.

ABRÃO, Bernardina F. F. Da educação, da cultura e do desporto. Constituição da República Federativa do Brasil de 1988. In: MACHADO, Antônio Cláudio da Costa (Org.); FERRAZ, Anna Cândida da Cunha (Coord.). Constituição Federal interpretada: artigo por artigo, parágrafo por parágrafo. 5. ed. Barueri, SP: Manole, 2014. p. 1-1175. Art. 205. Seção I Da Educação. Capítulo III Da educação, cultura e do desporto.

ACQUAVIVA, Marcus Cláudio. Dicionário jurídico Acquaviva. 4.ed. atual. e ampl. São Paulo: Rideel, 2010.

BRASIL. Constituição da República Federativa do Brasil (1988). Disponível em: <http://www.planalto.gov.br/ccivil_03/constituicao/ConstituicaoCompilado.htm>. Acesso em: 17 dez.2016.

DINIZ, Maria Helena. Dicionário jurídico universitário. São Paulo: Saraiva, 2010. 
DOUZINAS, Costas. O fim dos direitos humanos. Tradução de Luzia Araújo. São Leopoldo: Unisinos, 2009.

FREIRE, Paulo. Conscientização: Teoria e prática da libertação. São Paulo: Cortez \& Moraes, 1980.

GABRICH, Frederico de Andrade (Org.). Análise estratégica do direito. Belo Horizonte: Universidade FUMEC. Faculdade de Ciências Humanas e Sociais, 2010.

GABRICH, Frederico de Andrade. Transdiciplinaridade no ensino jurídico. In: XXII ENCONTRO NACIONAL DO CONPEDI - CURITIBA, Curitiba, PR: 2013, GT: DIREITO, EDUCAÇÃO, ENSINO E METODOLOGIA JURÍDICOS.

Disponível em: <http://www.publicadireito.com.br/artigos/?cod=57db7d68d5335b52>. Acesso em: 01 jul.2017.

HOUAISS, Antônio. Minidicionário Houaiss da língua portuguesa. 3.ed.rev. e aumentada. Rio de Janeiro: 2008.

JAPIASSU, Hilton. MARCONDES, Danilo. Dicionário básico de filosofia. 3.ed. rev. e ampliada - Rio de Janeiro: Jorge Zahar Editor, 1996.

LENZA, Pedro. Direito constitucional esquematizado. 18.ed. São Paulo: Saraiva, 2014.

MENDES, Gilmar Ferreira. BRANCO, Paulo Gustavo Gonet. Curso de direito constitucional. 9.ed. revista e atualizada. São Paulo: Saraiva, 2014.

NICOLESCU, Barasab. O manifesto da Transdisciplinaridade. São Paulo: Triom, 1999.

ORGANIZAÇÃO DAS NAÇÕES UNIDAS. Declaração Universal dos Direitos Humanos. Disponível em: <http:// http://www.ohchr.org/EN/UDHR/Documents/UDHR_Translations/por.pdf> Acesso em 20 maio.2017.

ORGANIZAÇÃO DAS NAÇÕES UNIDAS. Pacto Internacional dos Direitos Econômicos, Sociais e Culturais. $\quad$ Disponível em: <http://www.unfpa.org.br/Arquivos/pacto_internacional.pdf> Acesso em: 20 maio.2017.

SENA, Max Emiliano da Silva. O trabalho digno como meio de inclusão social no ordenamento jurídico brasileiro. In: XXV CONGRESSO NACIONAL DO CONPEDI CURITIBA, Curitiba, PR: 2016, p. 57-76. Disponível em:

<http://www.conpedi.org.br/publicacoes/02q8agmu/zwub6y85/f8C4j78b9mY3cgvo.pdf://ww w.conpedi.org.br/publicacoes/c178h0tg/ey04hoar/t7Xz107QhZ8Vs3yo.pdf>. Acesso em: 01.jul.2017.

SIDOU, J. M. Othon. Dicionário jurídico. 3.ed. Rio de Janeiro: Forense Universitária, 1995.

Rev. de Direitos Fundamentais nas Relações do Trabalho, Sociais e Empresariais | e-ISSN: 2525-9903 | Maranhão | v. 3 | n. 2 | p. 23 - 44 | Jul/Dez. 2017. 
SILVA, José Afonso da. Curso de direito constitucional positivo. 30.ed. São Paulo: Malheiros, 2008. 